УДК 612.64:[611.13/.16+616-018]

ХАРАКТЕРИСТИКА РАЗВИТИЯ СОСУДОВ ЭМБРИОНА ЧЕЛОВЕКА

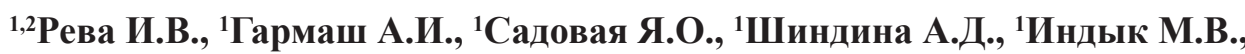

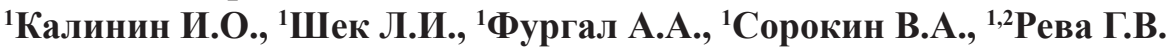

${ }^{1}$ ФАОУ ВО «Дальневосточный федеральный университет», Владивосток,

e-mail: RevaGal@yandex.ru;

${ }^{2}$ Международный научно-образовательный центр, Ниигата, е-mail: avers2@yandex.ru

Для создания фундаментальной платформы по внедрению клеточных технологий в лечение сосудистой патологии необходимо исчерпывающее знание и понимание процессов эмбрионального васкулогенеза и механизмов постнатального ангиогенеза. Противоречивые данные не только по механизмам индукции и ингибирования развития сосудов, но и источников развития эндотелия, противоречия в сроках эмбрионального васкулогенеза, и даже по размерам эмбриона в разные сроки, особенно в самый ранний сразу после имплантации, тормозят развитие не только ангиологии, но и трансплантологии. Клеточные взаимодействия в условиях васкулогенеза изучены в эксперименте на лабораторных животных, а полученные результать только условно могут быть экстраполированы на человека. На материале эмбриона человека установлено, что васкулогенез в различных органах имеет морфологические отличия, в сердце, печени и нервной трубке кровеносные сосуды отсутствуют, а первичные капилляры идентифицируются в экто- и мезенхиме. Идентификация клеток с рецепторами CD68 и CD163 свидетельствует об их участии в морфо- и васкулогенезе. Полученные данные об особенностях васкулогенеза в различных органах эмбриона человека способствуют пониманию органной специфичности эндотелия.

Ключевые слова: кровеносный сосуд, капилляр, эндотелий, сосудистая инволюция, запустевание сосудов, васкулогенез, механизмы ангиогенеза, стволовые клетки, циркулирующие эндотелиальные клетки

\title{
THE VESSELS DEVELOPMENT CHARACTERISTICS IN THE HUMAN EMBRYON
}

${ }^{1,2}$ Reva I.V., ${ }^{1}$ Garmash A.I., ${ }^{1}$ Sadovaya Ya.O., ${ }^{1}$ Shindina N.D., ${ }^{1}$ Indyk M.V., ${ }^{1,2}$ Kalinin I.O., ${ }^{1}$ Shek L.I., Furgal A.A., ${ }^{1}$ Sorokin V.A., ${ }^{1,2}$ Reva G.V.

${ }^{1}$ Far Eastern Federal University, Vladivostok, e-mail: RevaGal@yandex.ru; 2International Medical Research and Education Center, Niigata,e-mail: avers2@yandex.ru

To create a fundamental platform for the introduction of cellular technologies in the treatment of vascular pathology, it is necessary to have an exhaustive knowledge and understanding of the processes of embryonic vasculogenesis and mechanisms of postnatal angiogenesis. Contradictory data not only on mechanisms of induction and inhibition of vascular development, but also sources of endothelial development, contradictions in the timing of embryonic vasculogenesis, and even embryo sizes at different times, especially in the earliest immediately after implantation, inhibit the development not only of angiology but also transplantology . Cell interactions in conditions of vasculogenesis have been studied in an experiment on laboratory animals, and the results obtained can only be conditionally extrapolated to humans. On the material of the human embryo it is established that vasculogenesis in various organs has morphological differences, in the heart, liver and neural tube there are no blood vessels, and the primary capillaries are identified in the ecto- and mesenchyme. Identification of cells with receptors CD68 and CD163 indicates their participation in morpho- and vasculogenesis. The data obtained on the features of vasculogenesis in various organs of the human embryo contribute to an understanding of the organ specificity of the endothelium.

Keywords: blood vessel, capillary, endothelium, vascular involution, vasal discharge, vasculogenesis, angiogenesis mechanisms, stem cells, circulating endothelial cells

Врожденные пороки развития сосудов являются причиной приблизительно $20 \%$ смертей в неонатальном периоде, а также занимают значительное место в практике акушерства и гинекологии, медицинской генетике, детской хирургии и ортопедии, патологической анатомии [1]. Аномалии развития артерий и вен, такие как агенезия, аплазия, артериальные и венозные аневризмы, недоразвитие клапанного аппарата вен возникают при нарушении образования сосудистых стволов. По данным Brewster L., Robinson S., Wang R., Griffiths S., Li H., Peister A., Copland I., McDevitt T. (2017) нарушения ангиогенеза, критичные для жиз- ни, наблюдаются среди населения в $1 \%$ случаев [2], а связанные с заболеванием периферических артерий - в $10 \%$ [3-5]. При этом традиционные варианты реваскуляризации возможны только у $50 \%$ пациентов, остальным потребуются методы клеточной терапии, с использованием клеток костного мозга, мезенхимальных стволовых клеток (мск), обладающих большим потенциалом в качестве альтернативы реваскуляризационной терапии [6]. Nguyen H.L., Boon L.M., Vikkula M. (2017) указывают на то, что возникают сосудистые аномалии как следствие неправильного развития и регуляции ангиогенеза [7]. Исследуя ангиогенез, 
Varazashvili M.N., Mchedlishvili G.I. (1991), Mchedlishvili G.I. (1996) пришли к выводу, что агрегация эритроцитов вызывает нарушения кровотока и ишемию [8-10].

Знания о патофизиологических основах сосудистых аномалий резко возросли за последние 5 лет, дополнив теорию эмбриогенеза сосудистой системы молекулярно-генетическими находками [11]. Нарушения общих внутриклеточных сигнальных путей, часто активирующие мутации, по мнению авторов новых концепций, вызывают эндотелиальную клеточную дисфункцию [12-14]. Mathiyalagan P., Liang Y., Kim D., Misener S., Thorne T., Kamide C.E., Klyachko E., Losordo D.W., Hajjar R.J., Sahoo S. (2017) большую роль отводят CD34 ${ }^{+}$ стволовым клеткам, которые, по их мнению, способны через паракринную секрецию влиять на ангиогенез. Подавляя и одновременно модулируя экспрессию генов, участвующих в ангиогенезе, ответственных за синтез сосудистого эндотелиального фактора роста, ангиопоэтина 1 и ангиопоэтина 2 (ANG1, ANG2), metallopeptidase 9 (MMP9), thrombospondin 1(TSP1), они оказывают терапевтический эффект при ишемии задних конечностей у мыши, что может быть перспективным для экстраполяции в медицинскую практику [15].

Предметом острых дискуссий является вопрос происхождения эндотелия. Rigato M., Fadini G.P. (2017) считают, что циркулирующие прогениторные клетки (circulating progenitor cells, $C P C$ ) и эндотелиальные прогениторные клетки (endothelial progenitor cells, EPC) являются незрелыми клетками, участвующими в сосудистой регенерации и связанными со многими аспектами макро-и микрососудистых заболеваний [16]. Lu W., Li X. (2017) считают стволовые/прогениторные клетки (VSCs) выполняющими ключевую роль в развитии организма и важным источником всех видов сосудистых клеток, необходимых для создания, поддержания, регенерации и ремоделирования кровеносных сосудов. Авторы выделяют четыре основных типа VSCs, в том числе эндотелиальные прогениторные клетки (Ерс), гладкие мышечные прогениторные клетки (SMPCs), перициты и мезенхимальные стволовые клетки (Мск) [17]. Lin C.S., Lue T.F. (2013) подвергают сомнению роль перицитов, как стволовых, с учётом экспериментальных доказательств их ингибирующих ангиогенез свойств и функционального разнообразия [18]. Мезенхимальные стволовые клетки (мск) существуют в большинстве тканей взрослого человека и располагаются вблизи или внутри кровеносных сосудов. Ibrahim M., Richardson M.K. (2017) свиде- тельствуют о важности изучения ангиогенеза, так как состояние этого вопроса тормозит развитие трансплантологии, методов репаративной регенерации во всех областях медицины, и на современном этапе имеет недостаточность в изучении на материале человека [19]. Guerin C.L., Rossi E., Saubamea B., Mignon V., Silvestre J.S., Smadja D.M. (2017), подтвердив результаты Банина В.В., Куприянова B.B., Karaganov J.L., Мчедлишвили, Welt с соавторами [20] выдвинули концепцию реваскуляризации критически ишемизированной конечности за счёт выделенных из костного мозга мелких эмбрионально подобных плюрипотентных эндотелиальных прогениторных клеток, способных дифференцироваться в эндотелиоциты с терапевтическим реваскуляризационным потенциалом [21].

Поскольку ангиодисплазии не относятся к казуистическим находкам, существует острая необходимость разработки стратегий консервативного лечения на основе клеточных технологий. Однако, по данным Kang J.M., Yoon J.K., Oh S.J., Kim B.S., Kim S.H. (2017), в клинической практике использование взрослых стволовых клеток имеет ряд ограничений, таких, как низкая выживаемость клетки и низкая терапевтическая эффективность [22]. Несмотря на значительные успехи в изучении ангиогенеза, наличие нескольких противоречивых концепций развития сосудов в теле эмбриона человека (из мезенхимы и целома), а также участия в ангиогенезе циркулирующих ангиобластов, свидетельствуют о том, насколько далека эта проблема от решения. Множество концепций ангиодисплазий учитывают экзо- и эндогенные, молекулярно-генетические, метаболические и другие факторы, которые на современном этапе не получили окончательного подтверждения, а теория эмбриогенеза сосудистой системы требует значительной доработки, поэтому гистогенез эндотелия на современном этапе является одной из важнейших проблем васкуло- и ангиогенеза [23]. Calderon G.A., Thai P., Hsu C.W, Grigoryan B., Gibson S.M., Dickinson M.E., Miller J.S. (2017) подтвердили исследования Banin V.V. [24]. Jeong H.W., Hernfndez-Rodriguez B., Kim J., Kim K.P., Enriquez-Gasca R., Yoon J., Adams S., Scholer H.R., Vaquerizas J.M., Adams R.H. (2017) указывают, что молекулярные механизмы, регулирующие эндотелиальную активность клеток на различных этапах сосудистого роста, ремоделирования, созревания и покоя, остаются неясными [25]. Васкуло- и ангиогенез представляют собой сложные процессы, которые требуют скоординированных изменений в эндотелиальных клетках [26]. Многочисленные 
гипотезы происхождения эндотелиоцитов трактуют их развитие в связи с теорией трех зародышевых листков [27]. Существенная роль кровеносных сосудов в тканях и органах человека, понимание функциональных свойств и основополагающей молекулярной основы VSC имеет решающее значение для фундаментальных исследований [28]. Современное неудовлетворительное состояние данных по вопросу эмбрионального ангиогенеза определило направление нашего исследования.

Цель исследования - изучить кровеносные сосуды эмбриона человека в эмбриональном периоде.

\section{Материалы и методы исследования}

Исследование выполнено с учётом положений Хельсинской декларации (2000) и с разрешением этического комитета ФГАОУ ВО «Дальневосточный федеральный университет». Биоптаты эмбрионов были получены в соответствии с приказом Минздравмедпрома РФ от 29.04.94 № 82 «О порядке проведения патологоанатомических вскрытий» и в соответствии с номенклатурой клинических лабораторных исследований МЗ РФ (приказ 21 февраля 2000 г. № 64). Изучен материал эмбрионов человека 3, 5, 8 недель эмбрионального развития. Распределение материала представлено в табл. 1.

В работе использованы классические морфологические методы исследования и иммуногистохимические для выявления локализации фагоцитов, имеющих рецепторы на маркеры CD68 и CD163 (табл. 2).

Возраст эмбрионов человека определяли методом Гроссера и по таблице, составленной на основании данных УЗИ, в зависимости от длины эмбриона (табл. 3, 4).

В работе использованы современные высокочувствительные иммуногистохимические методы EPOS и En Vision. С помощью иммунной гистохимии выявлены различные фенотипы клеток, несущих маркеры CD68, CD163 фирмы DAKO, для последующего сравнительного анализа динамики их количества в ранний период онтогенеза человека и в условиях раннего ангиогенеза. Все статистические данные получены с помощью компьютерного программного обеспечения микроскопа Olympus BX51и цифровой камеры CD25 фирмы Olympus.

Таблица 1

\begin{tabular}{|c|c|c|c|}
\hline \multirow{2}{*}{$\begin{array}{c}\text { Количество } \\
\text { материала }\end{array}$} & \multicolumn{3}{|c|}{ Возраст эмбрионов } \\
\cline { 2 - 4 } & 3 недели & 5 недель & 8 недель \\
\cline { 2 - 4 } & 12 & 11 & 14 \\
\hline Итого & \multicolumn{3}{|c|}{37} \\
\hline
\end{tabular}

Таблица 2

\begin{tabular}{|c|c|c|c|}
\hline Методы & Гематоксилин и эозин & CD68 & CD163 \\
\cline { 1 - 1 } Возраст/ количество & & & 5 \\
\hline 3 недели & 2 & 5 & 3 \\
\hline 5 недель & 3 & 5 & 6 \\
\hline 8 недель & 3 & 37 & \\
\hline Итого & \multicolumn{3}{|c|}{} \\
\hline
\end{tabular}

Определение возраста по диаметру плодного яйца

Таблица 3

\begin{tabular}{|c|c|c|}
\hline 0,8 см $=3$ нед. 3 дня & $2,7 \mathrm{~cm}=6$ недель & 4,7 см $=9$ недель \\
\hline $1,4 \mathrm{~cm}=4$ нед. 3 дня & $3,4 \mathrm{~cm}=7$ недель & $5,3 \mathrm{~cm}=10$ недель \\
\hline $2,0 \mathrm{~cm}=5$ нед. 5 дней & $4,0 \mathrm{~cm}=8$ недель & $6,0 \mathrm{~cm}=11$ недель \\
\hline
\end{tabular}

Таблица 4

Возраст эмбрионов и плодов человека по данным УЗИ

\begin{tabular}{|c|c|}
\hline $0,3 \mathrm{~cm}=3$ нед & $3,2 \mathrm{~cm}=8$ нед. 4 дня \\
\hline $0,4 \mathrm{~cm}=3$ нед. 1 день & $3,3 \mathrm{~cm}=8$ нед. 4 дня \\
\hline $0,5 \mathrm{~cm}=3$ нед. 4 дня & $3,4 \mathrm{~cm}=8$ нед. 5 дней \\
\hline $0,6 \mathrm{~cm}=3$ нед. 6 дней & $3,5-3,6 \mathrm{~cm}=9$ недель \\
\hline $0,7 \mathrm{~cm}=4$ нед. 2 дня & $3,7 \mathrm{~cm}=9$ недель \\
\hline
\end{tabular}

МЕЖДУНАРОДНЫЙ ЖУРНАЛ ПРИКЛАДНЫХ

И ФУНДАМЕНТАЛЬНЫХ ИССЛЕДОВАНИЙ № 3, 2018 


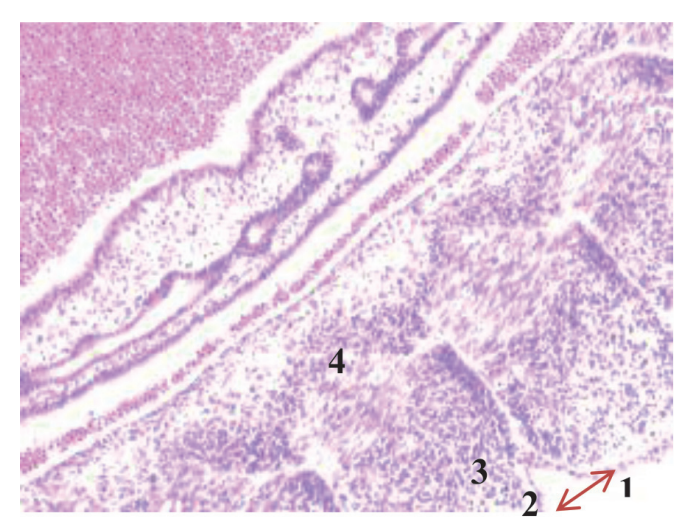

a)

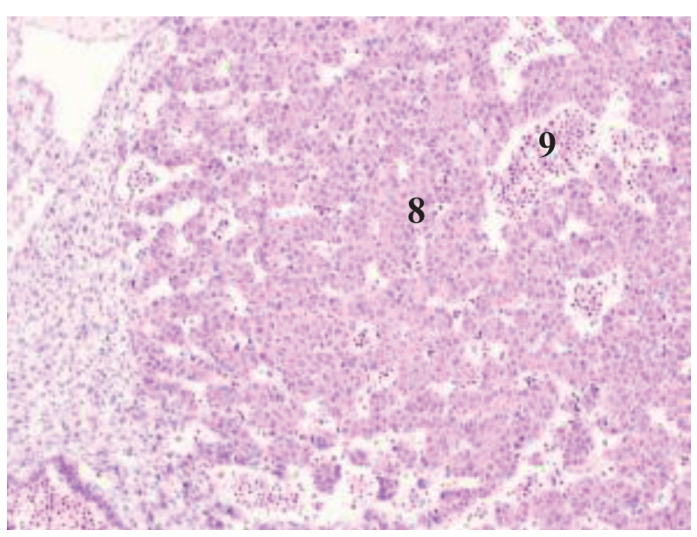

b)

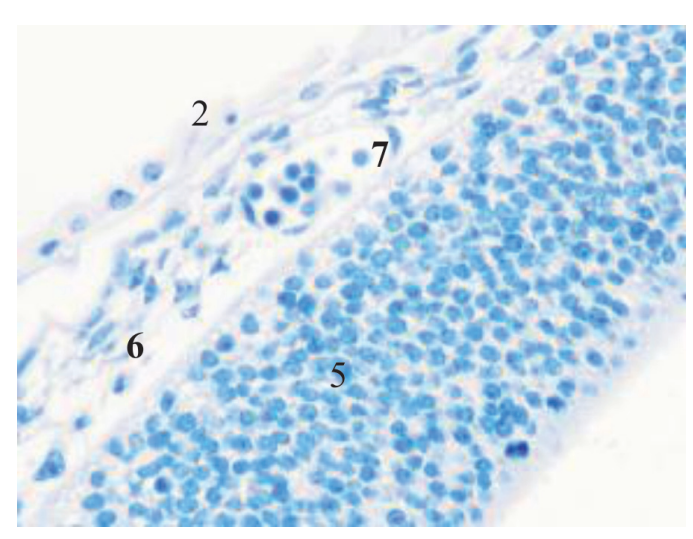

б)

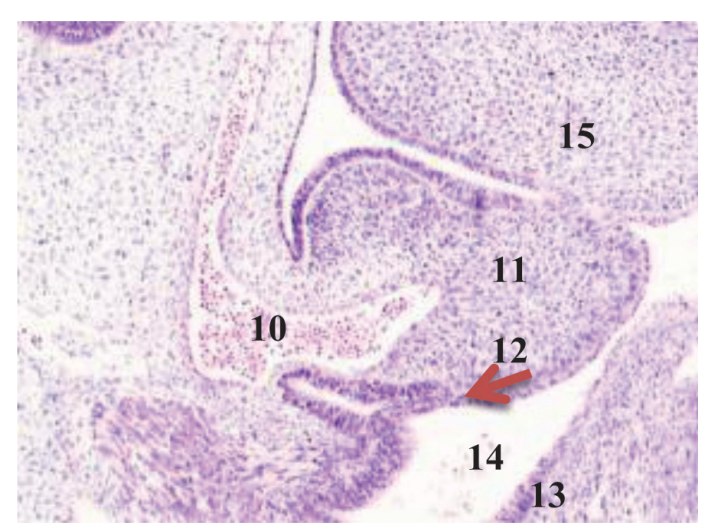

2)

Рис. 1. Эмбрион человека. Начало 4-й недели эмбрионального развития человека. а) сомиты мезодермы; б) нервная трубка; в) печень; г) сердие, лёгкое. Окраска гематоксилином и эозином (а, в, г); гематоксилином (в). Ув. (a, в, г) х100; (б) х200. 1. Сомиты мезодермы.

2. Эктодерма. 3. Мезодерма. 4. Энтодерма. 5. Нервная трубка. 6. Эктомезенхима.

7. Кровеносный сосуд. 8. Трабекулы гепатоиитов. 9. Синусоиды. 10. Аорта. 11. Миокард. 12. Эпикард. 13. Перикард. 14. Спланхнотом. 15. Лёгкое

\section{Результаты исследования и их обсуждение}

Нами установлено, что в конце 3-й - начале 4-й недели эмбрионального развития зародыш из 100-клеточного организма стремительно вырастает от 1,5 мм до 3,5 мм. На этом сроке начинается закладка всех систем будущего организма. Особенно важный этап - формирование нервной трубки, из которой в дальнейшем образуются головной мозг и вся нервная система. Головной конец эмбриона занимает больше половины всего объёма, около 2,5 мм, на туловище приходится 1,0 мм. В этот период углубляется желточная складка, образуется желточный стебель и наблюдается приподнятие заро- дыша в полости амниона (рис. 1, а). Сегментация дорсальной мезодермы достигает 10 сомитов, происходит её дифференцировка на миотом, склеротом и дерматом. В конце 3-й недели замыкается нервная трубка, увеличиваются мозговые пузыри на переднем полюсе эмбриона, отмечается закладка лёгкого, печени, сердца, поджелудочной железы и эндокринных желёз (рис. 1).

Именно в этот период происходят закладка и формирование кровеносных сосудов в различных отделах, как головного, так и туловищного отделов эмбриона. Отмечаются очаги формирования сосудов на переднем полюсе в области растущего переднего мозгового пузыря и в теле зародыша (рис. 2). 


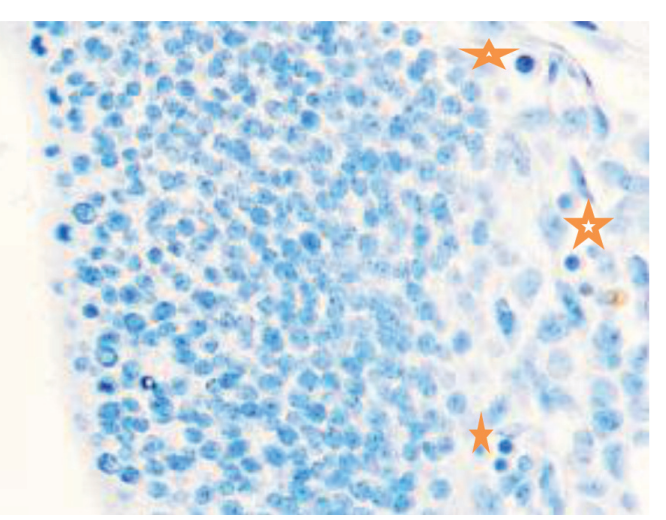

a)

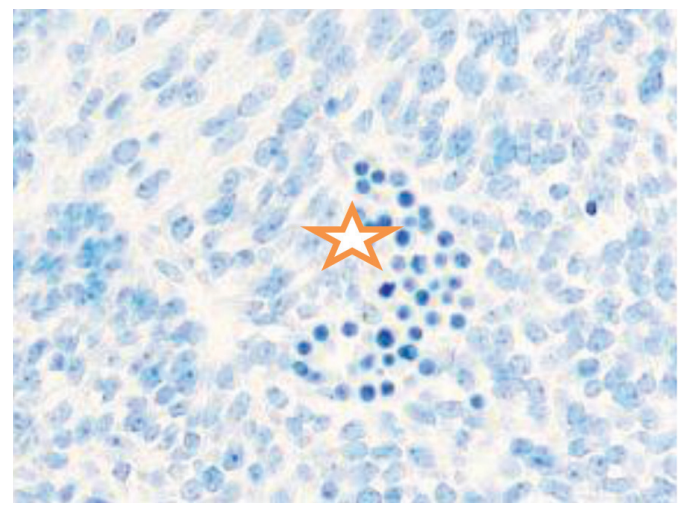

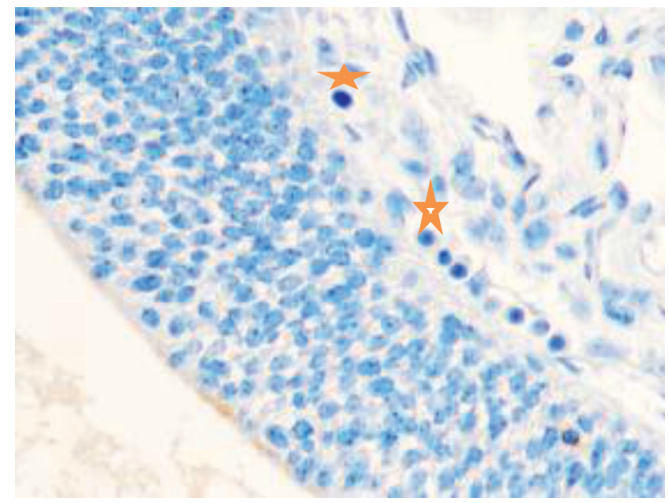

б)

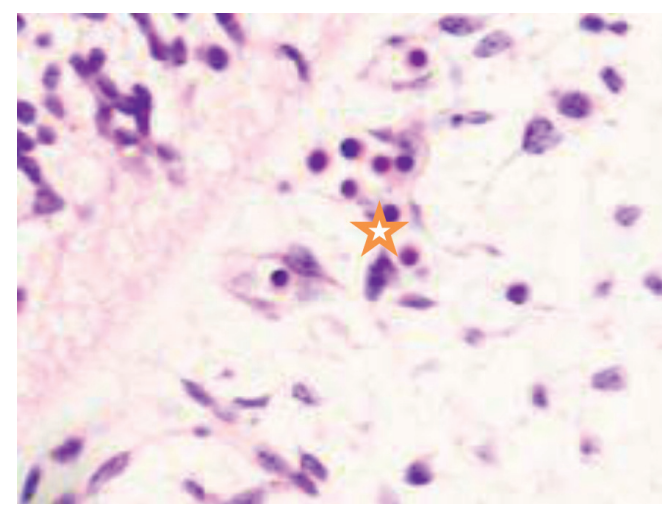

2)

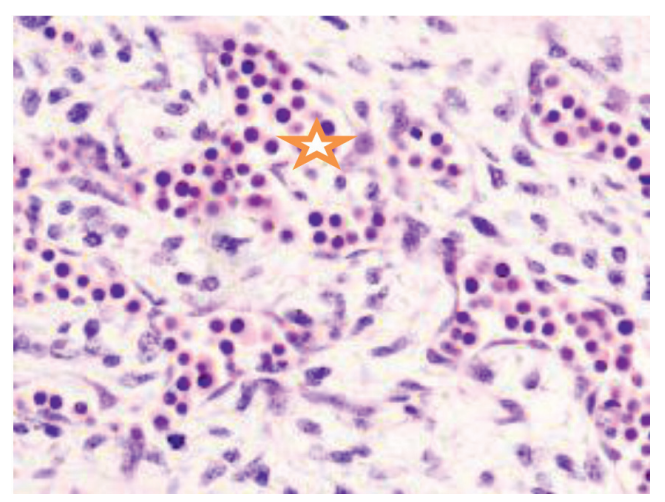

d)

Рис. 2. Эмбрион человека. Начало 4-й недели эмбрионального развития человека. а) передний мозговой пузырь; б) нервная трубка; в) мезодерма; г) мезенхима; д) в области перехода головного кониа эмбриона в туловишныи отдел. Звёздочками отмечены очаги васкулогенеза. Окраска гематоксилином и эозином (2, д); гематоксилином (а, б, в). Ув. х200

Следует отметить, что в ранние сроки эмбрионального развития в структуре нервной трубки и паренхиме сердца васкулогенез отсутствует. Трофика стенки формирующегося сердца в этот период осуществляется за счёт диффузии содержимого спланхнотома и просвета выходящей из верхушки сердца аорты. Также в отличие от других авторов, утверждающих, что в этот период в просвете формирующихся 
сосудов отсутствуют клетки, по нашим данным в них располагаются многочисленные мегалобласты. Более того, их заселение ткани в промежутках между клетками происходит до появления кровеносных сосудов. На этом этапе паренхима печени, представленная трабекулами гепатоцитов, имеет губчатое строение. В ячейках трабекулярных сетей пространства заполнены мегалобластами, часть из которых содержит крупные ярко окрашенные базофильные эксцентрично расположенные ядра и яркую оксифильную цитоплазму. Часть мегалобластов имеет признаки апоптоза, содержит пикнотизированные ядра. Также идентифицируются признаки митоза. Клетки c гомогенно окрашенными оксифильными ядрами крупнее клеток с бледно окрашенными и пикнотизированными ядрами в 1,5-2 раза. Периферия пространств, заполненных мегалобластами, представлена гепатоцитами, на некоторых участках уплощёнными Морфологическая картина печени эмбриона человека на 4-м месяце эмбриогенеза свидетельствует о том, что пространства, по которым циркулируют мегалобласты, ограничены уплощающимися гепатоцитами, в некоторых участках появляется мембрана. В рамках нашего исследования можно предположить, что кровеносные сосуды в структуре печени развиваются под влиянием взаимодействия мегалобластов и гепатоцитов. Кроме этого, в поле зрения идентифицируются безъядерные мегалоциты эллипсоидной формы, чаще полихроматофильные (рис. 3). В этот период развития они идентифицируются только в печени.

Принято считать, что в результате неизвестных пока механизмов вентральная эндодерма первичной кишки приобретает способность получать сигналы из мезодермы сердца. Эти сигналы в форме различных факторов роста фибробластов и белков - регуляторов морфогенеза кости вызывают спецификацию клеток, которые будут формировать печень, и активацию специфичных для печени генов. В моделях на животных отмечено, что такая спецификация происходит еще до образования видимого зачатка печени [29]. На следующем этапе эти новые специфицированные клетки мигрируют в краниальном и вентральном направлении в область поперечной перегородки, и к 4-й неделе беременности начинается морфогенез печени. Рост и развитие вновь образованного зачатка печени требует его взаимодействия с эндотелиальными клетками [30]. Мы не нашли подтверждения данных других авторов о том, что энтодермальные тяжи печени сталкиваются с блуждающими мезенхимными клетками с морфологией мелких лимфоцитов и эндотелиальными клетками врастающих капилляров. Сравнительный анализ собственных данных показал, что в печени не только нет мезенхимы, врастающих капилляров, но и мегалобласты заселяют пространства между трабекулами гораздо раньше, чем происходит васкулогенез в печени.

Особенностями развития сосудов в печени, сердце и развивающемся мозге эмбриона можно объяснить не только формирование капилляров синусоидного типа в печени, но и органную специфичность капилляров других органов человека.

Методом иммунной гистохимии на выявление локализации клеток, несущих рецепторы на CD68 и CD163, выявлено, что самый ранний период развития эмбриона человека характеризуется положительной экспрессией клеток в эктомезенхиме головного конца эмбриона, мезенхиме вокруг или вблизи очагов васкуляризации в теле эмбриона человека (рис. 4).

Нами отмечено, что в сосудах эмбриона отсутствуют клетки, имеющие положительную экспрессию на маркеры CD68 и $\mathrm{CD} 163$. Локализация маркеров отмечается исключительно вокруг или вблизи кровеносных сосудов. Также положительно экспрессируется часть клеток эктодермы головного конца эмбриона. В области сомитов эктодерма не содержит клетки, несущие маркеры CD68 и CD163.

Признанной концепцией считается утверждение о том, что сосудистая система (как кровеносная, так и лимфатическая) является одним из характернейших производных мезенхимы. По мнению большинства гистологов и эмбриологов, это относится, в частности, и к эндотелиальной выстилке сосудов. Наряду с этим существует предположение, что сосудистая система филогенетически возникла как система сильно разветвившихся выростов вторичной полости тела, или целома. Соответственно, эндотелиальная выстилка сосудов рассматривается как видоизменившийся в филогенезе целомический эпителий [31]. Возникновение сосудистого эндотелия из мезенхимы в эмбриогенезе, согласно утверждению Гаусманн, (1928), Н.Г. Хлопина, (1946), «является лишь кажущимся; в действительности же эндотелий сосудов берет начало из особого сосудистого зачатка - ангиобласта, клетки которого примешиваются к мезенхиме» Этот вопрос на современном этапе продолжает оставаться спорным и нуждается в дальнейшем экспериментальном выяснении. 


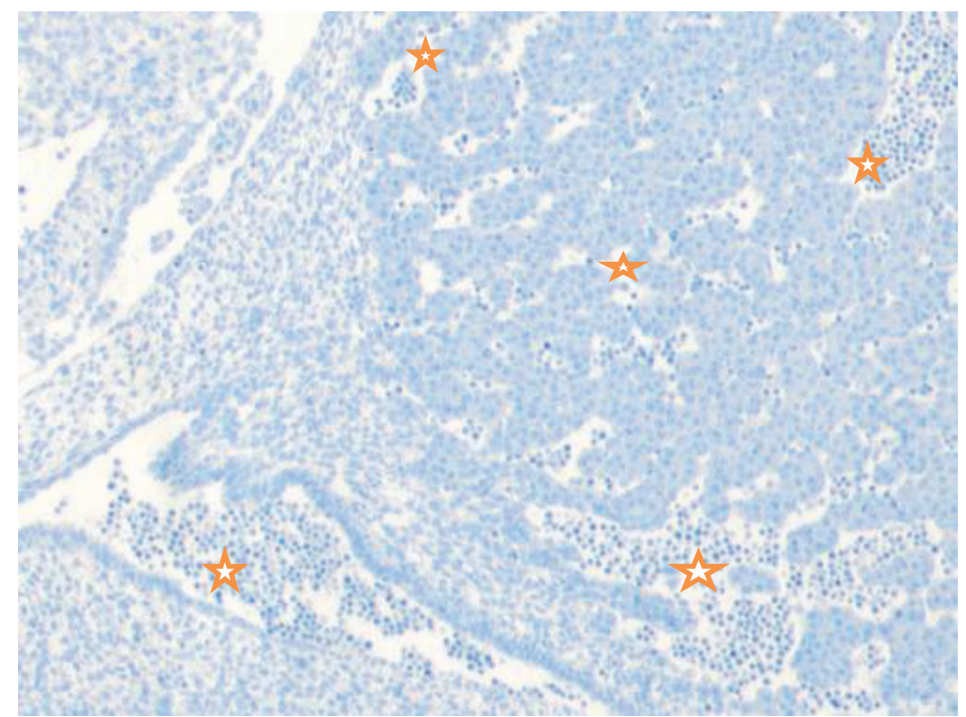

a)

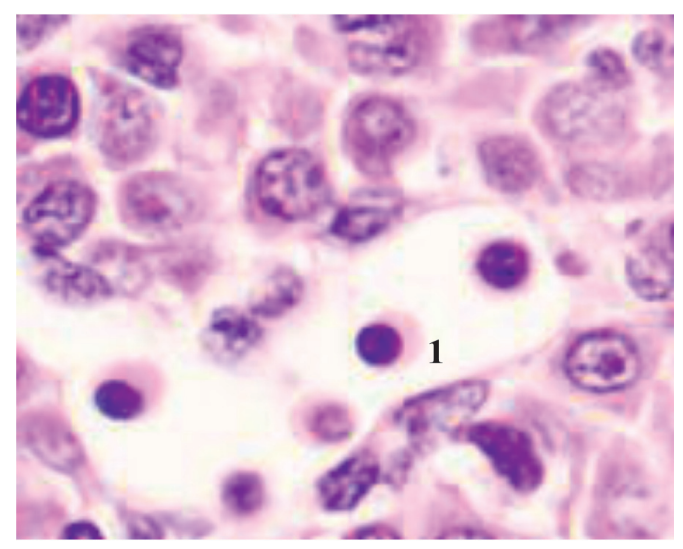

б)

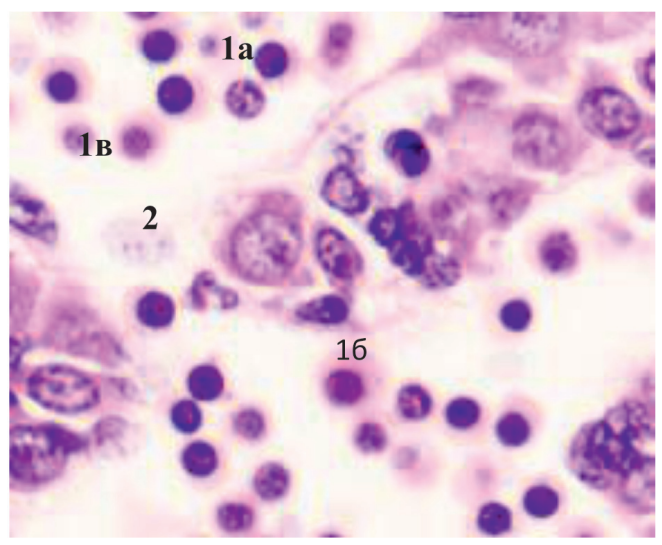

6)

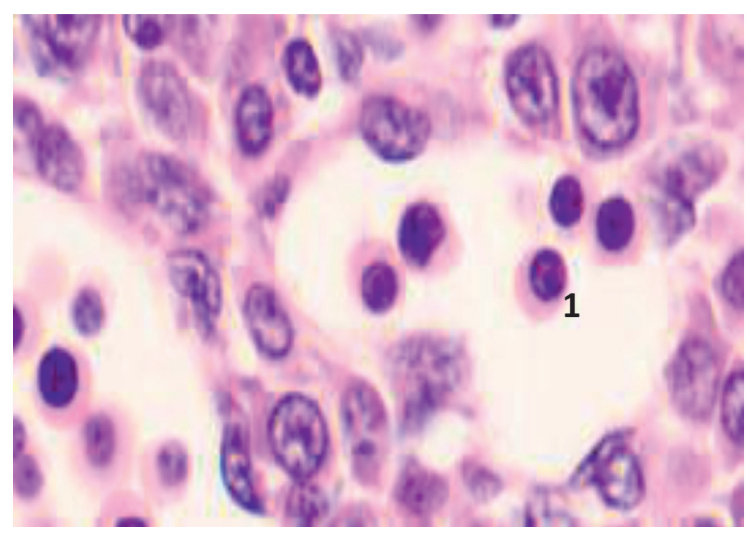

2)

Рис. 3. Эмбрион человека. Начало 4-й недели эмбрионального развития человека. Окраска гематоксилином и эозином. А) Печень с формируюшимися трабекулами из гепатоиитов.

Звёздочками отмечены пространства между трабекулами гепаточитов, заполненньх мегалобластами. 1. Мегалобласты:: а) пикноз ядер; б) крупные клетки, в) мелкие клетки; в) гепатоцииты. 2. Мегалоцичт. Ув. а) х100; б, в, г) х400 


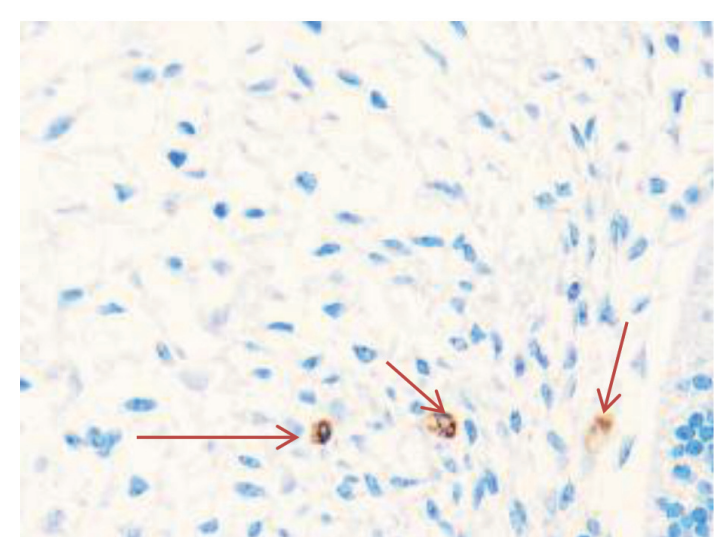

a)

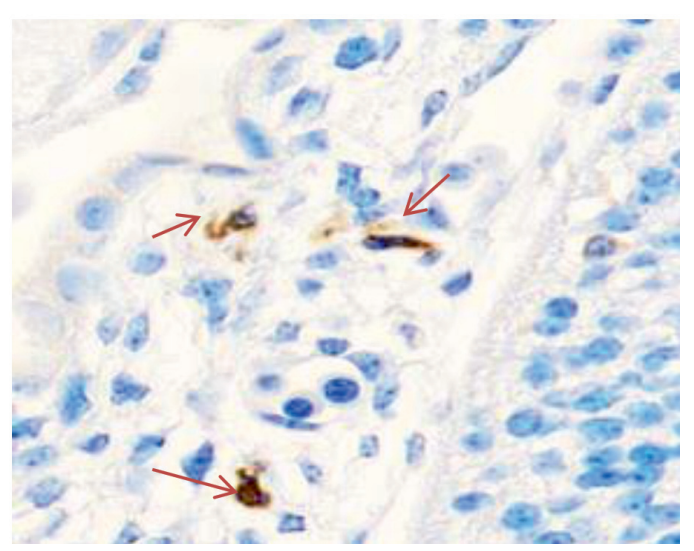

в)

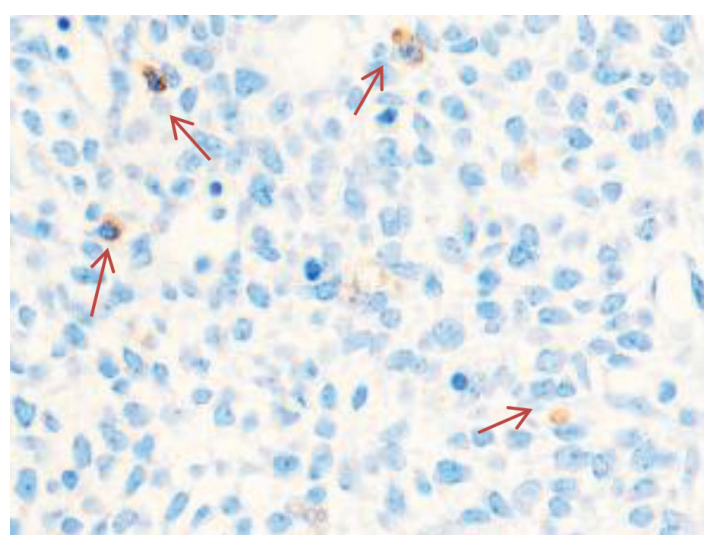

б)

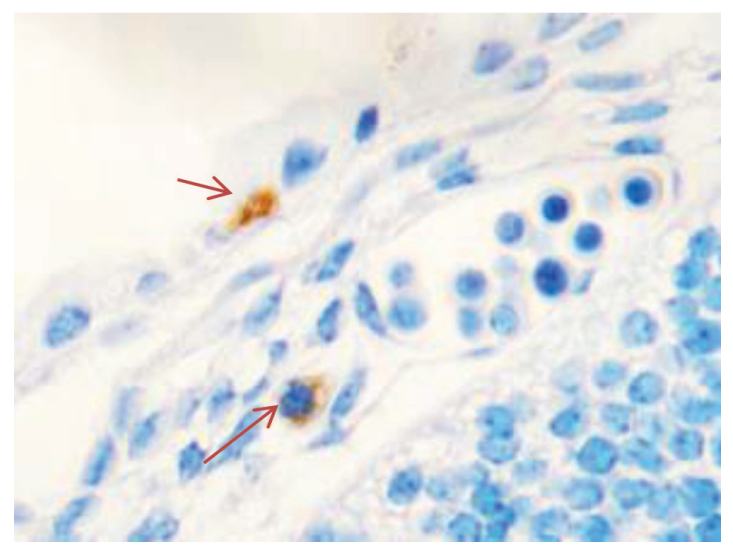

2)

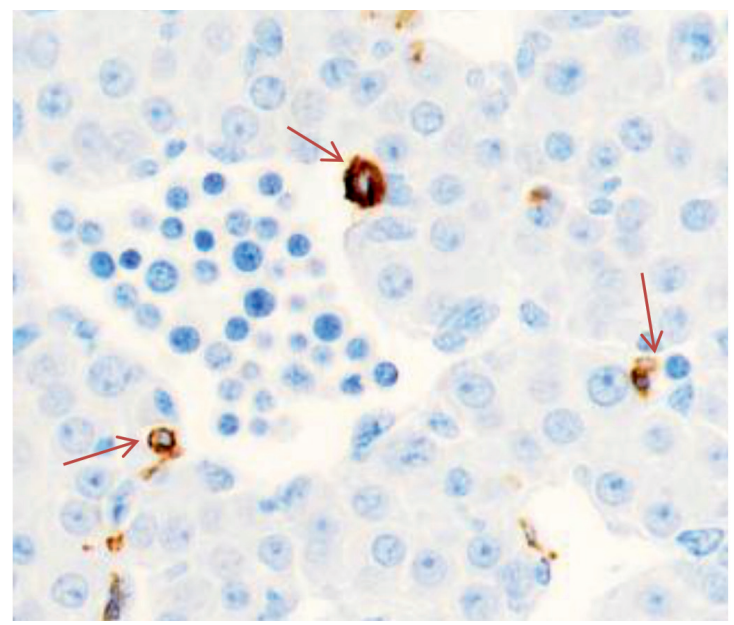

d)

Рис. 4. Эмбрион человека. Начало 4-й недели эмбрионального развития человека.

а) Мезенхима без сосудов; б) васкулогенез в мезенхиме; в, г) васкулогенез в эктомезенхиме. Иммунная гистохимия на выявление локализащии CD68 и CD163. Стрелками указань экспрессированные клетки. а, б-CD68; в, г-CD163. Ув. а, б) х200; в, г) $x 400$ 
По А.Г. Кнорре (1967), первые сосуды у зародышей высших позвоночных появляются в мезенхиме внезародышевых частей - желточного мешка, а, в частности, у высших приматов и человека - также хориона. В мезенхимном слое стенки желточного мешка и хориона сосуды возникают в форме плотных клеточных кучек - кровяных островков, сливающихся далее в сеть, причем периферические клетки перекладин этой сети, уплощаясь, дают начало эндотелию, а глубжележащие, округляясь, кровяным клеткам. В теле же зародыша сосуды развиваются в форме трубок, не содержащих кровяных клеток. Лишь позднее, после установления связи сосудов тела зародыша с сосудами желточного мешка, с началом биения сердца и возникновения кровотока, кровь попадает из сосудов желточного мешка в сосуды зародыша [31].

По другим данным, сосудистая система эмбриона закладывается на 5-10-й неделе внутриутробного развития в виде массы ангиобластических клеток, из которых в дальнейшем развивается капиллярная сеть, представляющая собой единую недифференцированную первичную сосудистую систему зародыша. Постепенно из нее образуются артериальные и венозные стволы с сохраненными между ними сетями шунтов. Далее некоторые артериальные стволы подвергаются обратному развитию или остаются в рудиментарном состоянии, другие же выливаются во вновь образованные сосуды. Отклонение от нормального развития кровеносных сосудов влечет за собой возникновение количественных и качественных изменений [32].

По нашим данным, сосуды в теле зародыша развиваются в конце 3-й - начале 4-й недели, после миграции мегалобластов, васкулогенез характеризуется сосудами с просветом, заполненным мегалобластами. В то время как в эктомезенхиме головного конца эмбриона и в мезенхиме его тела идентифицируются сосуды, в мезодерме, стенке сердца, нервной трубке и в печени они отсутствуют. В печени мегалобласты располагаются в просветах между трабекулами из дифференцирующихся гепатоцитов. Мезенхимоциты характеризуются положительной экспрессией на CD68 и CD163, в то время как мегалобласты не несут рецепторов на маркеры CD68 и CD163, функция антигенпрезентации и фагоцитоза является исключительной принадлежностью клеток формирующихся тканей развивающегося организма. Первыми экспрессируются клетки в эктомезенхиме головного конца эмбриона, затем в мезенхиме его тела, в дососудистый период, и вокруг сосудов в пе- риод васкулогенеза. В этот срок развития выражена экспрессия и репрессия генов, осуществляются клеточные иммунные реакции. Полученные данные подтверждают роль клеток, несущих маркеры CD68 и CD163 в морфогенезе и васкулогенезе.

Изучение васкулогенеза имеет огромное значение, так как постнатальный ангиогенез происходит под влиянием тех же индукторов и ингибиторов. В последнее время наблюдается значительный прогресс в изучении ангиогенеза, концепция об исключительном врастании в опухоль сосудов опровергнута и получены новые представления о механизмах формирования сосудов опухолей: миграция ангиобластов, что можно рассматривать в рамках нашей концепции эмбрионального васкулогенеза.

Работа выполнена при поддержке $\mathrm{Ha}$ учного фонда ДВФУ, в рамках государственного задания от 2014/36 до 2019 гг.

\section{Список литературы}

1. Kupatadze D.D., Nabokov V.V., Malikov S.A., Polozov R.N., Kanina L.Ia., Veselov A.G. Current problems in the reconstructive surgery of the locomotor apparatus in children // Vestn. Khir. Im. I.I. Grek. 1997; 156(2):94-6.

2. Brewster L., Robinson S., Wang R., Griffiths S., Li H., Peister A., Copland I., McDevitt T. Expansion and angiogenic potential of mesenchymal stem cells from patients with critical limbischemia // J. Vasc. Surg. 2017 Mar; 65(3):826-838.e1. DOI: $10.1016 /$ j.jvs.2015.02.061

3. Banin VV. Role of pericytes in mechanism of vessel neovascularisation in the regenerating connective tissue // Morfologiia. 2004; 125(1):45-50.

4. Banin V.V., Senatova I.D., Zaĭtsev K.T. Changes in the venular epithelium of the mesentery in rats after application of hydrogen peroxide // Biull Eksp Biol Med. 1988 Oct; 106(10):498-502.

5. Liu X., Li Q., Niu X., Hu B., Chen S., Song W., Ding J., Zhang C., Wang Y. Exosomes Secreted from Human-Induced Pluripotent Stem Cell-Derived Mesenchymal Stem Cells Prevent Osteonecrosis of the Femoral Head by Promoting Angiogenesis // Int J Biol Sci. 2017 Feb 6; 13(2):232-244. DOI: $10.7150 /$ ijbs. 16951 .

6. Tournois C., Pignon B., Sevestre M.A., Al-Rifai R., Creuza V., Poitevin G., Francois C., Nguyen P. Cell therapy in critical limb ischemia: A comprehensive analysis of two cell therapy products // Cytotherapy. 2017 Feb; 19(2):299-310. DOI: 10.1016/j.jcyt.2016.10.013.

7. Nguyen H.L., Boon L.M., Vikkula M. Vascular Anomalies Caused by Abnormal Signaling within Endothelial Cells: Targets for Novel Therapies // Semin Intervent Radiol. 2017 Sep; 34(3):233-238. DOI: 10.1055/s-0037-1604296.

8. Varazashvili M.N., Mchedlishvili G.I. The hematocrit in the microcirculatory bed of the brain // Fiziol. Zh SSSR Im I.M. Sechenova. 1991 Jun; 77(6):12-9.

9. Mchedlishvili G.I. Disturbances of the normal structuring of the blood flow in the microvessels as the cause of hemorheological disorders // Fiziol. Zh Im I M Sechenova. 1996 Dec; 82(12):41-7.

10. Mchedlishvili G.I. The concept of the structuring of the blood flow in microvessels // Fiziol. Zh. Im I.M. Sechenova. 1995 Jun; 81(6):48-53.

11. Catani L., Sollazzo D., Bianchi E., Ciciarello M., Antoniani C., Foscoli L., Caraceni P., Giannone F.A., Baldassarre M., Giordano R., Montemurro T., Montelatici E., D’Errico A., 
Andreone P., Giudice V., Curti A., Manfredini R., Lemoli R.M. Molecular and functional characterization of CD133<sup $>+</$ sup $>$ stem/progenitor cells infused in patients with end-stage liver disease reveals their interplay with stromal liver cells Cytotherapy. 2017 Sep 13. pii: S1465-3249(17)30660-6. DOI 10.1016/j.jcyt.2017.08.001

12. Dreyer C.H., Kjaergaard K., Ditzel N., Jorgensen N.R., Overgaard S., Ding M. Optimizing combination of vascular endothelial growth factor and mesenchymal stem cells on ectopic bone formation in SCID mice// J Biomed Mater Res A. 2017 Sep 6. DOI: 10.1002/jbm.a.36195.

13. Caporali A., Martello A., Miscianinov V., Maselli D., Vono R., Spinetti G. Contribution of pericyte paracrine regulation of the endothelium to angiogenesis // Pharmacol Ther. 2017 Mar; 171:56-64. DOI: 10.1016/j.pharmthera.2016.10.001.

14. Mathiyalagan P., Liang Y., Kim D., Misener S. Thorne T., Kamide C.E., Klyachko E., Losordo D.W., Hajjar R.J. Sahoo S. Angiogenic Mechanisms of Human CD34<sup $>+<$ sup $>$ Stem Cell Exosomes in the Repair of Ischemic Hindlimb // Circ Res. 2017 Apr 28; 120(9):1466-1476. DOI: 10.1161/CIRCRESAHA.116.310557.

15. Rigato M., Fadini G.P. Circulating stem/progenitor cells as prognostic biomarkers in macro- and microvascular disease. A narrative review of prospective observational studies.// Curr Med Chem. 2017 Sep 20. DOI: 10.2174/0929867324666 170920154020 .

16. Lu W., Li X. Vascular stem/progenitor cells: functions and signaling pathways // Cell Mol Life Sci. 2017 Sep 27. DOI 10.1007/s00018-017-2662-2.

17. Wu Q.H., Ma Y., Ruan C.C., Yang Y., Liu X.H., Ge Q., Kong L.R., Zhang J.W., Yan C., Gao P.J. Loss of osteoglycin promotes angiogenesis in limb ischaemia mouse models via modulation of vascular endothelial growth factor and vascular endothelial growth factor receptor 2 signalling pathway // Cardiovasc Res. 2017 Jan; 113(1):70-80. DOI: 10.1093/cvr/cvw220.

18. Lin C.S., Lue T.F. Defining vascular stem cells // Stem Cells Dev. 2013 Apr 1; 22(7):1018-26. DOI: 10.1089/ scd.2012.0504

19. Ibrahim M., Richardson M.K. Beyond organoids: In vitro vasculogenesis and angiogenesis using cells from mammals and zebrafish // Reprod Toxicol. 2017 Jul 8. pii: S0890 6238(17)30173-9. DOI: 10.1016/j.reprotox.2017.07.002.

20. Guerin C.L., Rossi E., Saubamea B., Cras A., Mignon V., Silvestre J.S., Smadja D.M. Human very Small Embryonic-like Cells Support Vascular Maturation and Therapeutic Revascularization Induced by Endothelial Progenitor Cells // Stem Cell. 2017 Aug; 13(4):552-560. DOI: 10.1007/s12015017-9731-7.

21. Welt K., Schippel K., Mironov V.A., Mironov A.A., Alimov G.A., Bobrik I.I., Banin V.V., Karaganov J.L. Vascular endothelium (review). I. General morphology. 2A: histogenesis of the vascular endothelium // Gegenbaurs Morphol Jahrb. 1990; 136(2):163-99.
22. Kang J.M., Yoon J.K., Oh S.J., Kim B.S., Kim S.H. Synergistic Therapeutic Effect of Three-Dimensional Stem Cell Clusters and Angiopoietin-1 on Promoting Vascular Regeneration in Ischemic Region // Tissue Eng Part A. 2017 Sep 26. DOI: 10.1089/ten.TEA.2017.0260.

23. Banin V.V., Muller F.S. Effect of hydrogen peroxide on the permeability of the walls of the mesenteric venules for fluorescein // Fiziol Zh SSSR Im I M Sechenova. 1988 Aug; 74(8):1149-57.

24. Calderon G.A., Thai P., Hsu C.W., Grigoryan B., Gibson S.M., Dickinson M.E., Miller J.S. Tubulogenesis of co-cultured human iPS-derived endothelial cells and human mesenchymal stem cells in fibrin and gelatin methacrylate gels // Biomater Sci. 2017 Jul 25; 5(8):1652-1660. DOI: 10.1039/c7bm00223h.

25. Jeong H.W., Hernandez-Rodríguez B., Kim J., Kim K.P., Enriquez-Gasca R., Yoon J., Adams S., Scholer H.R., Vaquerizas J.M., Adams R.H. Transcriptional regulation of endothelial cell behavior during sprouting angiogenesis // Nat Commun. 2017 Sep 28; 8(1):726. DOI: 10.1038/s41467-01700738-7.

26. Du W., Zhang K., Zhang S., Wang R., Nie Y., Tao H., Han Z., Liang L., Wang D., Liu J., Liu N., Han Z., Kong D., Zhao Q., Li Z. Enhanced proangiogenic potential of mesenchymal stem cell-derived exosomes stimulated by a nitric oxide releasing polymer // Biomaterials. 2017 Jul; 133:70-81. DOI: 10.1016/j.biomaterials.2017.04.030

27. Bianconi V., Sahebkar A., Kovanen P., Bagaglia F., Ricciuti B., Calabro P., Patti G., Pirro M. Endothelial and cardiac progenitor cells for cardiovascular repair: A controversial paradigm in cell therapy // Pharmacol Ther. 2017 Aug 19. pii: S01637258(17)30214-0. DOI: 10.1016/j.pharmthera.2017.08.004.

28. Bikfalvi A. History and conceptual developments in vascular biology and angiogenesis research: a personal view // Angiogenesis. 2017 Jul 24. DOI: 10.1007/s10456-017-9569-2.

29. Putman D.M., Cooper T.T., Sherman S.E., Seneviratne A.K., Hewitt M., Bell G.I., Hess D.A. Expansion of Umbilical Cord Blood Aldehyde Dehydrogenase Expressing Cells Generates Myeloid Progenitor Cells that Stimulate Limb Revascularization // Stem Cells Transl Med. 2017 Jul; 6(7):1607-1619. DOI: $10.1002 / \mathrm{sctm} .16-0472$.

30. Rossi E., Smadja D., Goyard C., Cras A., Dizier B., Bacha N., Lokajczyk A., Guerin C.L., Gendron N., Planquette B., Mignon V., Bernabeu C., Sanchez O., Smadja D.M. Co-injection of mesenchymal stem cells with endothelial progenitor cells accelerates muscle recovery in hind limb ischemia through an endoglin-dependent mechanism // Thromb Haemost. 2017 Aug 3; 117(10). DOI: 10.1160/TH17-01-0007.

31. Кнорре А.Г. Краткий очерк эмбриологии человека с элементами сравнительной, экспериментальной и патологической эмбриологии. - 1967. - С. 202-209.

32. Robertson D.J. Congenital arteriovenous fistulae of the extremities // J. Cardiovasc Surg (Torino). 1965 Sep-Oct; 5(6):Suppl:237-40. 